\title{
Parasitologia desenhada: uma ferramenta auxiliar no aprendizado de discentes do curso de medicina veterinária
}

\author{
Isabella Vilhena Freire Martins ${ }^{1}$, Jankerle Neves Boeloni ${ }^{1}$, josileia curty de oliveira ${ }^{1}$, Michel \\ Kobelinski $^{2}$, and Cíntia das Chagas Bernardo ${ }^{1}$ \\ ${ }^{1}$ Ensino \& Pesquisa \\ ${ }^{2}$ Affiliation not available
}

July 6,2020

\begin{abstract}
Drawn Parasitology: an auxiliary tool in the learning of students of the veterinary medicine

The purpose of this goal was to introduce a tool to promote greater learning and fixation of the content of the discipline of veterinary parasitology, through the didactic game "Drawn Parasitology". The game was developed based on the design and guessing of parasites based on morphological characteristics. The game was applied for nine consecutive years, totaling 441 students involved and it was possible to observe that there were changes in the teacher-student interaction, using the most pleasant teaching and learning processes. The game is a proposal to support the pedagogical practice of teachers in the teaching and learning processes of students in parasitology content, as a valid and positive playful activity for the appropriation of knowledge, the development of creativity and the encouragement of socialization; therefore its methodology can be recommended for Higher Education and can be applied in several other subjects and areas of knowledge.
\end{abstract}

Keywords: university education. ludic. active learning.

\section{Resumo}

O objetivo deste estudo foi apresentar uma ferramenta para auxiliar o processo de ensino-aprendizagem e promover maior fixação do conteúdo da disciplina Parasitologia Veterinária, por meio do jogo didático "Parasitologia desenhada". O jogo foi desenvolvido baseado em desenho e adivinhação de parasitos a partir de características morfológicas. A metodologia foi aplicada durante nove anos consecutivos, totalizando 441 alunos envolvidos sendo possível observar melhora na interação professor-aluno, tornando os processos de Ensino e Aprendizagem mais prazerosos. O jogo é uma proposta de apoio à prática pedagógica docente na disciplina de parasitologia veterinária, como uma atividade lúdica válida e positiva à apropriação do conhecimento, ao desenvolvimento da criatividade e estímulo à socialização; por isso sua metodologia é recomendada para o Ensino Superior e pode ser aplicada em diversas outras disciplinas e áreas do conhecimento.

Palavras-chave: ensino superior. lúdico. metodologia ativa.

\section{Autores}

Isabella Vilhena Freire Martins. Professora Associado IV do Departamento de Medicina Veterinária da Universidade Federal do Espírito Santo - Campus Alegre, ES. Doutora em Sanidade Animal e pesquisadora do Programa de Pós Graduação em Ciências Veterinárias da UFES. ivfmartins@gmail.com

Cintia das Chagas Bernardo. Professora Titular das Faculdades Integradas da América do Sul, Caldas Novas, GO. Doutora em Medicina Tropical e Saúde Pública. cintiachagasbernardo@gmail.com 
Jankerle Neves Boeloni. Professora Adjunto II do Departamento de Medicina Veterinária da Universidade Federal do Espírito Santo - Campus Alegre, ES. Doutora em Patologia Animal e pesquisadora do Programa de Pós Graduação em Ciências Veterinárias da UFES. jankerle@gmail.com

Josiléia Curty de Oliveira. Secretária executiva da Secretaria Única de Graduação da UFES - Campus Alegre, ES. Licenciada em Letras e Pedagogia e Mestre em Gestão Pública pela UFES. josileiacoliveira@gmail.com

\section{Introdução}

Diante da crescente demanda por profissionais na área da saúde mais versáteis e humanizados é visível a necessidade de mudanças nos modelos de ensino-aprendizagem utilizados na formação desses profissionais (CYRINO; TORALLES-PEREIRA, 2004). Atualmente, os docentes têm buscado vivenciar novas formas de ensinar como alternativas em suas práticas aplicadas em sala de aula, o que tornou a missão de um educador mais desafiadora. O docente deixa de ser o transmissor dos conteúdos programáticos de uma disciplina, mas trabalha como mediador do processo de ensino-aprendizagem exaltando a preocupação com a formação humana dos alunos (GROSSI, 2017). A situação motivadora que deu origem a este estudo partiu da observação dos autores, ao perceber a necessidade de aplicar uma técnica nova como ferramenta para auxiliar em sala de aula, tornando o estudo do componente curricular parasitologia veterinária mais atraente aos alunos do curso de medicina veterinária.

A disciplina de Parasitologia Veterinária, alvo do presente estudo, é ofertada aos alunos do $3^{\circ}$ período do curso de bacharelado de Medicina Veterinária ofertado pela Universidade Federal do Espírito Santo, Campus de Alegre, com carga horária de 105 horas. O ementário da disciplina propõe o estudo protozoários, artrópodes e helmintos de interesse da Medicina Veterinária. A disciplina tem como principais objetivos fornecer ao aluno conhecimentos sobre a parasitologia, englobando seus conceitos e relações, apresentando os principais grupos de parasitos, com ênfase na morfologia e nos ciclos biológicos. Desse modo, o aprendizado a disciplina propõe o conhecimento de inúmeros conceitos e formas, muitas vezes dificultando a sua fixação, compreensão e aprendizagem.

Como se tornou um desafio ensinar assuntos tão complexos, optou-se por utilizar, como ferramenta auxiliar, um jogo adaptado com uso de desenho, para despertar o interesse dos alunos e fixar a morfologia dos parasitos estudados. Nesse sentido, a utilização dos jogos no processo de ensino-aprendizagem universitário é objeto de estudo deste artigo.

Mesmo que ainda seja pouco utilizada, a ludicidade é um assunto que vem ganhando espaço no âmbito da educação universitária, pelo fato de os jogos fazerem parte da essência do mundo das pessoas, e por sua utilização permitir um trabalho pedagógico que possibilita o acesso e a produção do saber. Pizutti et al. (2018), em seu estudo, buscaram discutir sobre ferramentas didático-pedagógicas capazes de aprimorar o desejo de aprender e ensinar por docentes e discentes de medicina veterinária, na disciplina de Parasitologia Veterinária, no entanto vale ressaltar que ainda há poucos trabalhos na literatura referentes ao estudo da parasitologia no ensino superior.

A utilização do lúdico no processo de ensino da parasitologia vem sendo aplicado principalmente para o público infantil, não só como forma de aprendizado, mas também para a prevenção de doenças (ALMEIDA et al., 2012; BRAGAGNOLLO et al., 2019). Entretanto, modelos de ensino que proporcionem uma aprendizagem mais dinâmica e atraente são demandadas para a formação de profissionais éticos e competentes, capazes de lidar com as mais variadas situações do dia a dia também vem sendo aplicados nas aulas de cursos de graduação.

Dessa maneira, o objetivo geral deste artigo foi apresentar a ferramenta utilizada nas aulas de Parasitologia Veterinária a fim de demonstrar a aplicabilidade do Jogo didático "Parasitologia Desenhada" utilizado como uma proposta para promover um maior aprendizado e fixação do conteúdo de Parasitologia Veterinária visto em sala de aula, por alunos do curso de medicina veterinária.

\section{As novas metodologias de ensino-aprendizagem no ensino superior}


Diante da crescente demanda por profissionais mais versáteis e humanizados, é visível a necessidade de mudanças nos modelos de ensino-aprendizado utilizados na formação desses profissionais (CYRINO; TORALLES-PEREIRA, 2004). Sabendo que a universidade é um espaço não só de aprendizado, mas também de convivência, é crescente a discussão sobre um ensino mais eficiente e que faça sentido para o aluno (VERÍSSIMO; SANTOS, 2016). A visão do professor como provedor e o aluno como receptor do conhecimento está em desuso e novas metodologias pedagógicas têm tido como foco o discente (MACEDO et al., 2018).

No contexto contemporâneo, tem crescido a importância de se determinar a didática abordada em sala de aula demonstrando o real papel do docente e como novas metodologias de ensino-aprendizagem podem auxiliar no processo de formação de alunos universitários (BORGES; ALENCAR, 2014). É imperativo que o educando se torne o protagonista da sua formação, sendo o docente um facilitador, gerando situações críticas e estimuladoras (CUNHA, 2012).

Veríssimo e Santos (2016) acreditam que a formação profissional não deve estar pautada apenas em ensino e produção, mas também com outros elementos formadores. Assim, novas formas de aprendizagem são oferecidas aos discentes a fim de que busquem promover diferentes habilidades e competências advindos das relações sociais dos indivíduos, são as chamadas metodologias ativas (BORGES; ALENCAR, 2014). Essas metodologias possuem caráter crítico-reflexivo e têm sido utilizadas como fortalecedoras do vínculo professor-aluno, proporcionando uma aula mais prazerosa e atraente (ROSA, 2017; MACEDO et al., 2018).

Métodos mais dinâmicos despertam o interesse do discente proporcionando a ele o desenvolvimento de diferentes competências (FORTUNA et al., 2017). FREEMAN et al. (2004) citam que além de melhorar o desempenho do aluno em avaliações, a utilização de metodologias ativas diminui o número de desistências do curso. Segundo dados do Censo da Educação Superior 2018 (INEP, 2019), mais da metade dos estudantes ingressantes em 2010 desistiram do curso e apenas $38 \%$ o concluíram.

A proposta atual para o ensino superior é proporcionar ao aluno um ensino construtivista, que auxilie na formação de profissionais capazes de lidar com as diferentes situações do dia a dia (BORGES; ALENCAR, 2014). Nesse sentido, a utilização de jogos didáticos como método de ensino coloca o docente em posição de condutor, motivador e avaliador da aprendizagem (CUNHA, 2012). A interação social proporcionada pelas metodologias ativas é capaz de promover melhoras de desempenho do discente como, por exemplo, na memorização e socialização (CUNHA, 2012; NOJOSA et al., 2009).

\section{O uso de jogos no ensino superior como recurso didático no processo ensino-aprendizagem}

Por muito tempo, a aprendizagem acontece com base na repetição de conteúdos com metodologias tradicionais de ensino. Entretanto, com a mudança do perfil dos estudantes do ensino superior, surgiu a necessidade de novas formas de trabalhar os conteúdos, os quais não são atingidos pelo modo tradicional. A preocupação maior em relação a este novo perfil de alunos é como abordar de uma maneira interessante os conteúdos propostos obtendo a atenção desses alunos (COVOS et al., 2018).

Dessa forma, o desafio de centrar o interesse do estudante nos conteúdos passou a ser um desafio à competência do docente e não mais do aluno. Ou seja, o interesse do aluno em aprender passou a ser o objetivo principal do processo de ensino e aprendizagem, e o professor passou a ser o protagonista de situações estimuladoras para a aquisição de conhecimentos (CUNHA, 2012).

Para isso, novas técnicas estão sendo aplicadas visando envolver os alunos e despertar maior interesse pelo que estão aprendendo, desenvolvendo a criatividade promovendo assim a participação ativa do discente no processo ensino-aprendizagem. Neste artigo, o jogo é abordado como um recurso didático no ensino superior como instrumento motivador para a aprendizagem de conhecimentos, à medida que propõe estímulo ao interesse do estudante.

De acordo com a literatura, o jogo quando utilizado como recurso didático é uma ferramenta que proporciona aos alunos outras formas de aprendizagem de conceitos e desenvolvimento de valores. Esses recursos podem contribuir no processo de ensino-aprendizagem, diferenciando-se das demais atividades de ensino, pois pode 
apresentar característica lúdica. Novos recursos didáticos como os jogos podem atingir vários objetivos como o estimulo à aquisição do conhecimento, à capacidade cognitiva dos alunos e à interação entre professor/aluno. Assim, isto é o que diferencia os jogos das metodologias tradicionais normalmente utilizadas e se identifica com uma abordagem ativa e social (CUNHA, 2012).

De acordo com Cunha (2012), o jogo pode possuir funções educativas e lúdicas, dependendo da forma pela qual a atividade é executada. Quando o objetivo é somente de ensinar é considerado educativo, mas se também apresentar a função de diversão, pode ser considerado lúdico. Por isso, é importante equilibrar as funções educativa e lúdica a fim de que não se torne apenas um jogo e fuja do objetivo educacional. Ramos et. al. (2017) afirmam que a ludicidade possibilita a socialização e proporciona prazer quando é executada. Portanto, apresenta-se como uma importante ferramenta de ensino e pode ser utilizada como atividade de fortalecedora do processo de aquisição de conhecimentos sobre várias temáticas.

Segundo Cunha (2012), o jogo ajuda o estudante a construir novas formas de pensamento, desenvolvendo e enriquecendo sua personalidade, por outro lado, para o professor, o jogo o leva à condição de condutor, estimulador e avaliador da aprendizagem. Sendo assim, muitos docentes vêm desenvolvendo metodologias com base na aplicação de jogos em diferentes conteúdos, buscando melhorar o processo ensino aprendizagem, principalmente no Ensino Superior.

Bobrowski (2016) avaliou a aplicabilidade do Jogo "Baralho do DNA" para alunos em uma turma de Agronomia da Universidade Federal de Pelotas e concluiu que o jogo promove a socialização do conhecimento e ao mesmo tempo motiva os alunos na aprendizagem dos conceitos dos conteúdos da disciplina Genética Molecular. Com esse estudo, o autor afirma que a proposição de atividades lúdicas no Ensino Superior é válida e se diferencia, positivamente, da forma expositivo-dialogada muito comum no ambiente acadêmico.

Lozza e Rinaldi (2017) investigaram como a utilização de metodologias ativas/jogos está sendo utilizados por universitários e seus docentes para o processo de construção de conhecimento na disciplina de Metodologia da Pesquisa Científica em um Centro Universitário em Curitiba-PR. Os resultados encontrados nesse estudo ratificam as conclusões de outras pesquisas no sentido de que docentes e alunos aprovam a utilização do jogo como estratégia metodológica de ensino.

Lazmar Filha et al. (2017) estudaram os jogos no processo de ensino-aprendizagem universitário, cuja delimitação contempla os jogos como ferramenta pedagógica universitária, por meio de um estudo de caso da utilização dos jogos de montar Lego $®$ no curso de logística de uma universidade particular na cidade de Manaus. O objetivo desse estudo foi demonstrar a aplicabilidade dos jogos Legoß como ferramenta pedagógica no processo ensino-aprendizagem no ensino superior. Os autores puderam comprovar que se pode ensinar por meio dos recursos como os jogos. Também relataram que já existe uma produção bibliográfica sobre a aplicabilidade e eficácia dos jogos no processo de ensino-aprendizagem nas universidades, no entanto esses estudos pouco tenham influenciado na prática da educação superior nas universidades.

Melo, Ávila e Santos (2017) apresentaram em seu estudo que os jogos educativos têm sim a sua eficácia no processo de ensino aprendizagem e pode também melhorar o rendimento do aluno, pois é um meio de facilitar a aprendizagem de uma forma lúdica. Segundo os autores, o jogo didático promove uma melhor relação entre o professor e o aluno e também pode melhorar o rendimento do aluno, pois é um meio que facilita a aprendizagem de uma forma lúdica, aumentando a capacidade para resolver problemas.

Grossi (2017), em seu estudo, relatou experiências sobre atividades lúdicas nas salas de aula como recurso pedagógico no processo de ensino e aprendizagem dos alunos do Curso Técnico de Informática Industrial, do Programa Especial de Formação Pedagógica de Docentes e do Mestrado do Centro Federal de Educação Tecnológica de Minas Gerais. Os resultados desse estudo permitiram afirmar que a sala de aula pode e deve ser lugar alegre e prazeroso e os conteúdos das disciplinas podem ser apresentados aos alunos de forma alegre e cativante, independentemente do nível de ensino.

Covos et al. (2018) pesquisaram o novo perfil de alunos no ensino superior, e a utilização de jogos lúdicos para facilitação do ensino aprendizagem e verificaram que os jogos educacionais, quando bem utilizados 
no processo de ensino e aprendizagem, fazem com que o aluno tenha melhor percepção, compreensão e desenvolva competências ligadas à interpretação, aplicação e avaliação, além de promover a motivação e interação, fazendo com que os alunos se coloquem em situações reais do cotidiano, onde diversos problemas são pontuados.

O quadro 01 apresenta os fatores que instigam os alunos quando são aplicadas as técnicas lúdicas em sala de aula.

Quadro 01 - Fatores que instigam os alunos com a utilização de jogos lúdicos.

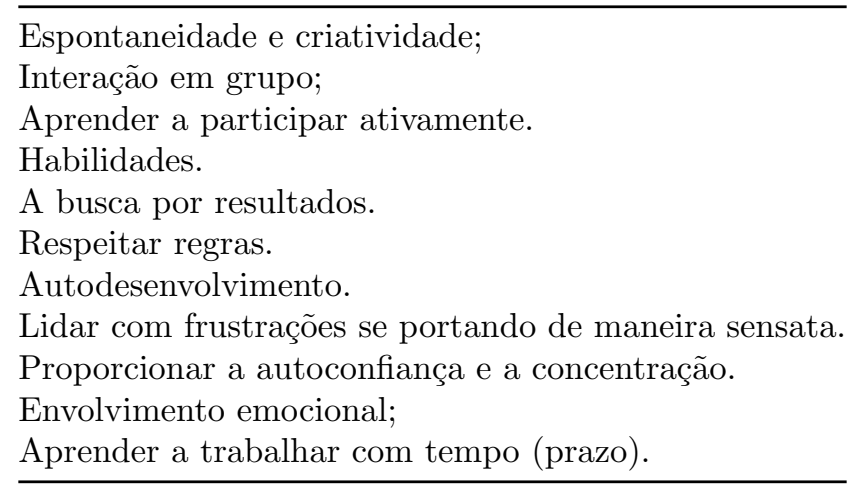

Fonte: Covos et al. (2018).

Atualmente, o jogo é um assunto de pesquisa crescente, principalmente porque é uma atividade pouco utilizada no Ensino Superior, apesar de se mostrar eficaz. Nesse sentido, estudos relatam que o jogo pode sim ser uma proposta que venha inovar o ensino em sala de aula, com o objetivo de desenvolver no aluno a reflexão e conscientização crítica e questionadora. Metodologias que baseiam-se no uso de raciocínio crítico e lógico demonstram ao estudante que o mesmo, a partir de seu aprendizado e seu conhecimento adquirido, pode resolver situações em seu dia a dia, sendo elas propostas pelos docentes ou originadas de seu cotidiano fora do ambiente de sala de aula (MELO; ÁVILA; SANTOS, 2017).

Covos et al. (2018) destacaram que existem diversos jogos que podem ser utilizados em sala de aula, entretanto, estes devem ser escolhidos de acordo com o perfil da sala, para que tenha o resultado esperado. Os autores também pesquisaram, em seu estudo, os jogos lúdicos mais utilizados pelos docentes no ensino superior, como uso de E-books, IPADs e Tablets, charadas, quebra-cabeças, teatralização, jogos de mímica, campeonatos e dinâmicas em grupo.

Os autores afirmam que as práticas lúdicas no ensino superior devem despertar o interesse do aluno para a aprendizagem, tornando a aula mais atraente, capaz de aproximá-lo o máximo possível da realidade, transformando os conteúdos em vivência. Entretanto, a forma de conduzir a aula dentro da sala é de responsabilidade do docente, que deverá ter conhecimento de maneiras e formas de tornar o aprendizado mais interessante e mais dinâmico. A utilização dessas técnicas de ensino dependem de alguns fatores como: do docente que a emprega; dos objetivos que se pretende alcançar; dos tipos de pessoas a que se destina; do conteúdo a ser tratado, e; do momento em que a técnica será aplicada (COVOS et al., 2018).

Sendo assim, Covos et al. (2018) orientam quanto a alguns cuidados que o docente precisa ter antes de trabalhar os jogos didáticos em sala de aula como a falta do conhecimento do docente sobre o jogo didático, a orientação inadequada sobre o jogo, a falha no estabelecimento de regras, e ainda a atuação inadequada do docente como medidor.

Cabe ressaltar também que nem todos os conceitos podem ser explicados por meio dos jogos e se o professor interferir com frequência, perde-se a ludicidade. Assim, destaca-se que a aprendizagem se constrói por meio de um processo interno do aluno, fruto de suas próprias experimentações, sendo que o professor atua como 
o mediador. O que leva à necessidade de proporcionar ao educando momentos de prazer e de experiências lúdicas, capazes de contribuir para o convívio social na universidade e na sociedade.

Fortuna et al. (2017) apresentaram resultados da aplicação do jogo ATPensando, elaborado para estimular e auxiliar o aprendizado do conteúdo de Bioquímica dos alunos do primeiro semestre do curso de Medicina. Os resultados apresentados demonstram maiores índices de acertos nos testes após a aplicação do jogo e o trabalho discute a importância do uso de jogos como ferramenta de ensino. Outros autores também utilizaram jogos didáticos para incentivar o aprendizado de alunos na área da bioquímica (MESTANZA, 2017; NOJOSA et al., 2009; FARKUN; PEREIRA-LEITE, 2014), química (RAMOS et al., 2017) e na área da saúde (CYRINO; TORALLES-PEREIRA, 2004; PIRES; GOTTEMS; FONSECA, 2017 e MACEDO et al., 2018).

Pizutti et al. (2018), ao trabalhar com a confecção de materiais didático-pedagógicos com alunos do curso de medicina veterinária, concluíram que a atividade foi positiva, e que os alunos participaram do processo de aprendizagem de uma forma ativa, ou seja, sendo autores e coautores no processo.

A formação de um profissional na área da saúde é extensa e desafiadora requerendo, assim, empenho por parte de docentes e discentes. Novos métodos de ensino que proporcionem um aprendizado mais efetivo e a construção de um profissional competente, ético e versátil são cada vez mais importantes no contexto atual. O desenvolvimento de diferentes competências e habilidades são uma ferramenta chave para a formação de um profissional de sucesso.

Coscrato, Pina e Melo (2010) realizaram um trabalho de levantamento das principais publicações do uso de ferramentas lúdicas na educação em saúde e concluíram que os estudos focaram na avaliação da aprendizagem de conteúdo sem, contudo, abranger sua utilização no ensino superior, e ressaltam que o ensino superior deve ser objeto de estudos posteriores.

\section{Material e Métodos}

Esta pesquisa é predominantemente qualitativa e se ampara nas reflexões e discussões de estudos presentes na literatura sobre prática de ensino-aprendizagem, metodologias ativas, jogos didáticos e ludicidade para construção do embasamento teórico.

Este artigo consiste na apresentação do desenvolvimento e aplicação do Jogo denominado Parasitologia Desenhada, adaptado pela docente da disciplina Parasitologia Veterinária do jogo Imagem \& Açãoß) (Grow Jogos e Brinquedos LTDA, São Bernardo do Campo, São Paulo), com a finalidade de reforçar as características morfológicas dos parasitos estudados na disciplina de Parasitologia Veterinária, ofertada para o $3^{\mathbf{0}}$ período do curso de Medicina Veterinária da Universidade Federal do Espírito Santo (UFES), Campus de Alegre, Espírito Santo.

O jogo foi desenvolvido utilizando recursos disponíveis noCampus, como papel cartão, papel adesivo, pincéis atômicos, e apagador. Foram confeccionadas 45 cartas contendo o nome genérico ou específico desses parasitos e foi aplicado sempre ao final da disciplina, quando os alunos já tiveram contato com todos os parasitos presentes nas cartas (Figura 1).

Figura 1 - Kit de cartas do jogo Parasitologia Desenhada 


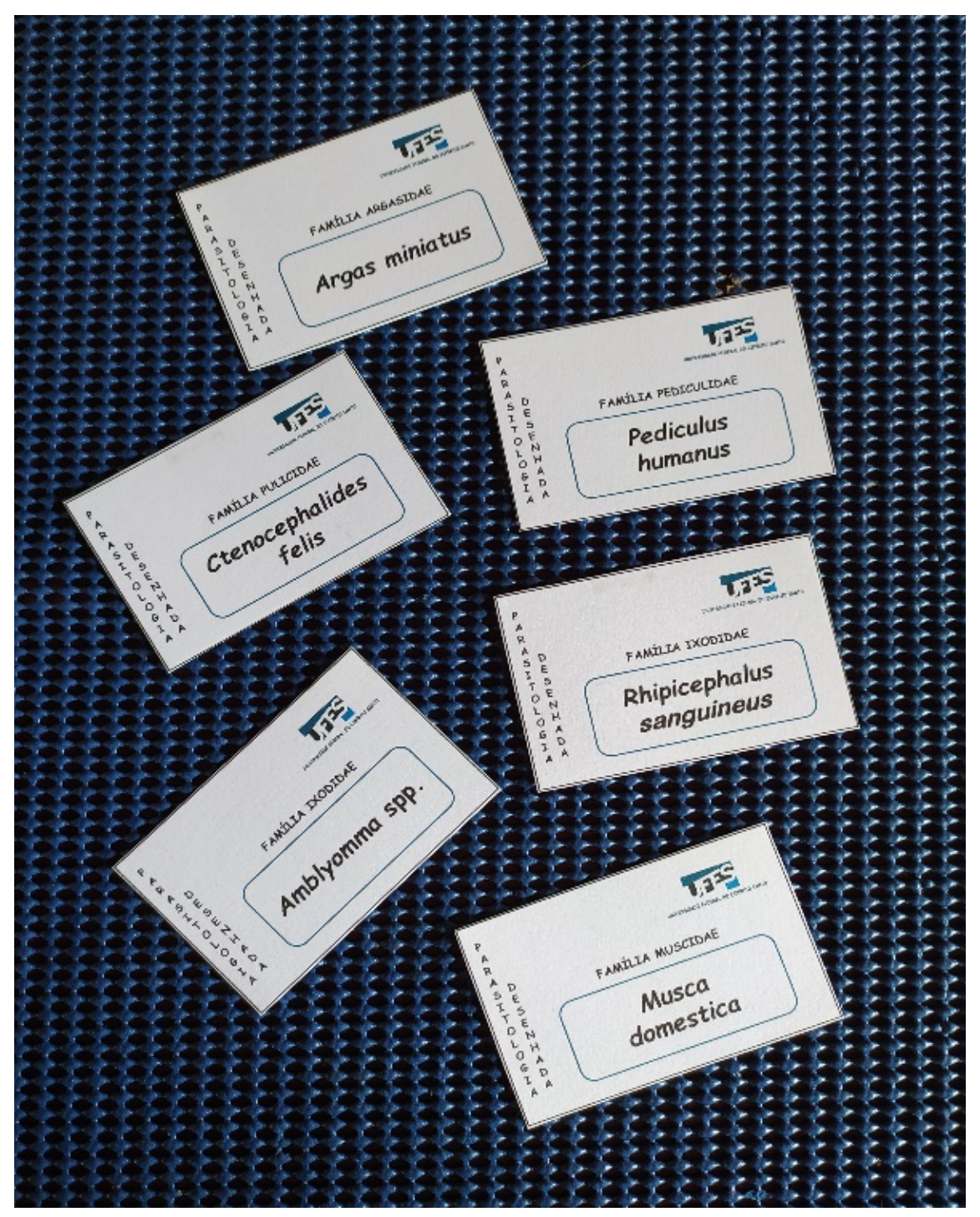

Fonte: Elaborado pelas autoras

Cada turma é dividida em equipes ordenadas de forma crescente, aleatoriamente, contendo cinco ou seis alunos. Para o início do jogo, a primeira equipe sorteia uma carta e elege o primeiro jogador. Este é responsável por desenhar características morfológicas do parasito sorteado na carta, para que os demais alunos da equipe adivinhem. Cada equipe tem um minuto para acertar o nome do parasito sorteado e não é permitido uso de letras, números e nem o uso de mímicas. Ao final do tempo, o professor avalia se a resposta está correta e, caso a equipe tenha acertado, ganha um ponto.

As equipes se revezam no sorteio das cartas de acordo com ordem definida inicialmente. Todos os alunos, em todas as equipes, sorteiam pelo menos uma carta a fim de que todos tenham a chance de desenhar e adivinhar. Ao final de todas as rodadas, a equipe que obtém o maior número de acertos é considerada a campeã do jogo.

Esse jogo didático geralmente é aplicado após o lançamento do conteúdo para explorar o conhecimento adquirido pelos alunos e auxiliar na fixação dos conceitos apresentados pelo docente.

A avaliação do jogo Parasitologia Desenhada é realizada por meio de registro fotográfico feito no momento 
da aplicação do jogo Parasitologia Desenhada e a partir de observações do docente quanto ao processo de aprendizagem durante e após a sua aplicação.

\section{Resultados e Discussão}

O jogo Parasitologia vem sendo utilizado por nove anos consecutivos em turmas do curso de Medicina Veterinária e abrangeu ao todo 441 participantes. A Figura 2 mostra o quantitativo de alunos que participaram da atividade nos anos entre 2011 a 2019.

Figura 2 - Número de alunos participantes por ano de aplicação do jogo Parasitologia Desenhada.

\section{[CHART]}

Fonte: Elaborado pelas autoras.

A aplicação do jogo "parasitologia desenhada" aos graduandos de medicina veterinária por nove anos consecutivos proporcionou resultados antes, durante e depois da realização do método. Antes da inserção do jogo, os alunos reconheciam os parasitos em aulas práticas, mas apesar de ser uma atividade prática, os mesmos não apresentavam motivação para manter o estudo da parasitologia em dia. A partir do conhecimento dos alunos sobre a realização do jogo ao final da disciplina, houve um empenho na memorização e aprendizado motivados principalmente pela competição. Além disso, era nítida a motivação durante a realização dos jogos, a disputa era sempre harmônica entre as equipes e o aprendizado dos alunos era muito perceptível.

Segundo Cunha (2012), a motivação dos alunos durante a utilização de jogos didáticos proporciona um aprendizado mais rápido e efetivo. É visível que em jogos pedagógicos não há perdedores, pois, todos se beneficiam com o conhecimento adquirido (ALMEIDA et al., 2012). Por diversas vezes foi notória a percepção dos alunos em pelo menos focar em características básicas de diferentes grupos, como a presença de quatro pares de patas em ácaros, corpo com flagelos em alguns protozoários, e essa percepção facilitou a descoberta pelos integrantes da equipe.

O lúdico é inerente às relações humanas e a utilização de métodos que envolvam características como criatividade, imaginação e emoções, são capazes de proporcionar muito mais do que apenas conhecimento (CUNHA, 2012; PIRES; GOTTEMS; FONSECA, 2017). Neto e Moradillo (2015) citam que os jogos didáticos precisam promover diversão, mas, acima de tudo aprendizado que leve ao desenvolvimento do discente.

Durante a realização do "Parasitologia desenhada", foi possível avaliar o aprendizado e memorização do conteúdo ministrado em sala de aula. Características como capacidade de socialização e concentração, ética, desenvoltura em situações de exposição e controle emocional puderam ser observados.

Uma das principais queixas dos alunos, de modo geral, é a dificuldade de permanecer focado na aula expositiva, principalmente naquelas muito longas. Foi observado que os alunos, durante os jogos, permaneciam concentrados no conteúdo abordado. Esse resultado corrobora com relatos de Neto e Moradillo (2015), quando aplicaram metodologias ativas a alunos de química. Em estudo realizado com mais de 200 alunos, Freeman et al. (2004), evidenciaram a melhora na performance daqueles alunos submetidos a metodologias ativas em detrimento daqueles que participaram apenas de aulas expositivas.

Após a realização do "Parasitologia desenhada", quando são discutidos em sala de aula assuntos abordados pelo jogo, notou-se os alunos com raciocínio rápido, mais confiantes e com atitudes positivas. Tais características são atribuídas às atividades em grupo (JENSEN; LAWSON, 2011) que proporcionam ao discente discutir e ouvir diferentes opiniões.

Essa análise com os alunos após a aplicação do jogo Parasitologia Desenhada possibilitou identificar que os alunos entenderam o objetivo do jogo e o consideraram aplicado à parasitologia. A maioria dos alunos afirmou que o jogo contribui para fixação do conteúdo da disciplina, que a aula fica mais interessante com o uso do jogo e se relaciona com o conteúdo da aula, o que facilita mais sua compreensão e aprendizagem do conteúdo dado. E isso corrobora com os resultados encontrados por Lozza e Rinaldi (2017) em que confirmam 
as conclusões de outras pesquisas no sentido de que professores e alunos aprovam a utilização do jogo como estratégia metodológica de ensino.

Observou-se também uma valorização da atividade lúdica aplicada nas aulas de Parasitologia Veterinária, uma vez que os alunos consideram que o jogo deveria ser usado mais vezes na disciplina e inclusive que fosse aplicado com maior frequência em outras disciplinas, o que corrobora com Cunha (2012), quando diz que os docentes podem utilizar jogos didáticos como auxiliares na construção dos conhecimentos em qualquer área de ensino.

Dessa forma, ressalta-se que com a aplicação dessa estratégia metodológica de ensino, as docentes participantes deste estudo acreditam no jogo como uma possibilidade de melhora nos resultados para o ensino da disciplina investigada, validando a opinião dos alunos que por sua vez também sinalizaram gostar do ensino por meio de uma forma lúdica, beneficiando o aprendizado e a aplicação do conhecimento de forma prática. Tudo isto pôde ser confirmado pelo estudo de Bobrowski (2016), que concluiu que o uso de atividades lúdicas no Ensino Superior é válida e se distingue, positivamente, das aulas expositivas comumente utilizadas no ambiente acadêmico.

É importante destacar que o docente que escolhe aplicar a atividade lúdica deve, necessariamente, desenvolver em si a capacidade de se flexibilizar e se adaptar a novos contextos. Precisa, assim, estar preparado para lidar com o inesperado, pois cada grupo de alunos é único e reage de forma diferente a cada atividade estabelecida, uma vez que foi possível observar que alguns alunos consideram como ponto negativo a questão da subjetividade do desenhista e outros ainda considera ser a aula expositiva a que se concentra melhor. Isso provavelmente se deve ao fato de os alunos terem mais contato com as técnicas tradicionalmente aplicadas nas salas de aulas ao longo da vida escolar (RAMOS et al., 2017).

Nesse sentido, Bobrowski (2016) destaca que todo o recurso didático depende da forma como é conduzido em sala de aula pelo docente, sendo sua participação como mediador indispensável para que os objetivos da atividade sejam alcançados com sucesso. Por isso, Cunha (2012) ressalta que é importante que a técnica, para ser considerada educativa, deve manter o equilíbrio entre a função lúdica e a educativa.

Também foi possível observar que, com a aplicação dessa ferramenta lúdica, houve melhora na interação professor-aluno, tornando os processos de ensino e aprendizagem mais prazerosos. Esses resultados também foram apontados em estudo realizado por Ramos et al. (2017) que o jogo e as atividades lúdicas puderam auxiliar no processo de ensino e aprendizagem, e mostraram também que essas ferramentas auxiliaram para que houvesse um maior diálogo e interação entre os alunos.

Assim, o Jogo Parasitologia Desenhada é uma proposta de apoio à prática pedagógica dos docentes nos processos de ensino e aprendizagem dos discentes em conteúdo de parasitologia, como uma atividade lúdica válida e positiva à apropriação do conhecimento, ao desenvolvimento da criatividade e estímulo à socialização, podendo ser utilizada em qualquer área de ensino na educação superior.

\section{Conclusão}

A metodologia lúdica proposta atingiu seu objetivo final de fixação da matéria, gerando interação entre os alunos e discussões sobre o conteúdo. Outros pontos positivos como visão crítica, competição e memória foram estimulados nos discentes envolvidos. Portanto, a dinâmica foi avaliada como positiva e motivadora aos discentes da disciplina de Parasitologia Veterinária, tornando-os mais receptivos à absorção do conteúdo.

A metodologia pode ser recomendada para o Ensino Superior e pode ser aplicada em diversas outras disciplinas e áreas do conhecimento, uma vez que o jogo possibilita a resolução de problemas e a tomada de decisões, além de desenvolver a curiosidade, a iniciativa, a interação e a autoconfiança, proporcionando o desenvolvimento da linguagem, do pensamento e da concentração.

\section{Referências}

ALMEIDA, R.A. et al. Jogo Parasitológico: uma estratégia no ensino-aprendizagem da parasitologia. Revista Rede de Cuidados em Saúde . v.6, n.1, 2012. Disponível em : 
http://publicacoes.unigranrio.edu.br/index.php/rcs/article/view/1613/841 Acesso em: 23 mar. 2020

BOBRoWSKI, V. L. O Uso do Lúdico no Ensino Superior: O Jogo "Baralho do DNA" Como Facilitador da Aprendizagem em Genética Molecular. In book: Educação: pesquisas, reflexões e problematizações, Publisher: PoloBooks, p. 210-246. 2016.

BORGES, T. S.; ALENCAR, G. Metodologias ativas na promoção da formação crítica do estudante: o uso das metodologias ativas como recurso didático na formação crítica do estudante no ensino superior.Cairu em Revista, v.3, n.4, p.119-143, 2014.

BRAGAGNOLLO, G. R. et al . Intervenção educativa lúdica sobre parasitoses intestinais com escolares. Revista Brasileira de Enfermagem , Brasília, v. 72, n. 5, p. 1203-1210, Oct. 2019. Disponível em: http://www.scielo.br/scielo.php?script=sci_arttext\&pid=S0034-71672019000501203\&lng=en\&nrm=iso Acesso em 29 Mar. 2020.

CUNHA, M. B. Jogos no ensino de química: considerações teóricas para sua utilização em sala de aula. Química Nova na Escola, v.54, n.2, 92-98, 2012.

CYRINO, E. G.; TORALLES-PEREIRA, M. L. Trabalhando com estratégias de ensino-aprendizado por descoberta na área da saúde: a problematização e a aprendizagem baseada em problemas. Caderno de Saúde Pública, v.20, n.3, p.780-788, 2004.

COSCRATO, G.; PINA, J. C.; MELlO, D. F. Utilização de atividades lúdicas na educação em saúde: uma revisão integrativa da literatura.Acta Paulista de Enfermagem , São Paulo, v. 23, n. 2, p. 257-263, Apr. 2010 . Disponível em: http://www.scielo.br/scielo.php?script=sci_arttext\&pid=S0103$21002010000200017 \& \operatorname{lng}=\mathrm{en} \& \mathrm{nrm}=\mathrm{iso}$. Acesso em 24 mar. 2020.

COVOS, J. S. et al. D. O novo perfil de alunos no ensino superior, e a utilização de jogos lúdicos para facilitação do ensino aprendizagem.Revista Saúde em Foco 2018. Disponível em: http://portal.unisepe.com.br/unifia/wp-content/uploads/sites/10001/2018/06/007_O_NOVO_PERFIL_DE_ALUNOS_NO_ENSINO_SUPERIOR.pdf Acesso em: 20 fev. 2020.

FARKUN, L.; PEREIRA-LEITE, C. Bioquim4x: um jogo didático para rever conceitos de bioquímica. Revista de ensino de Bioquimica , v.12, n.2, 2014. Disponível em: http://bioquimica.org.br/revista/ojs/index.php/REB/article/view/342/449. Acesso em: 12 jan. 2020.

FORTUNA, T. et al. ATPensando: jogo pedagógico no processo de ensino-aprendizagem de bioquímica. Colloquium Vitae, Presidente Prudente, SP, v.9, n. especial, p27-32, jun./dez. 2017.

FREEMAN, S. et al. Active learning increases student performance in science, engineering, and mathematics. Proceedings of the National Academy of Sciences, v.111, n. 23, p.8410-8415, 2014.

GROSSI, M. G. R. O lúdico na aprendizagem de alunos de cursos técnico, graduação e mestrado: relatos de experiências. RIAEE - Revista Ibero-Americana de Estudos em Educação , v. 12, n. 3, p. 1689-1709, jul-set/2017.

INEP, 2019. Disponível em: http://portal.inep.gov.br/artigo/-/asset_publisher/B4AQV9zFY7Bv/content/semdesistencias-numero-de-graduados-poderia-dobrar-no-brasil/21206 Acesso em: 29 set. 2019.

JENSEN, J. L.; LAWSON, A. Effects of Collaborative Group Composition and Inquiry Instruction on Reasoning Gains and Achievement in Undergraduate Biology. CBE-Life Sciences Education, v.10, n.1, p.64-73, 2011.

LASMAR FILHA, E. S., et al. Os jogos como ferramenta pedagógica universitária: um estudo de caso da utilização do LEGOß. Revista EDUCAmazônia , v.6, n.2, p.230-253, 2017.

LOZZA R.; RINALDI, P. O uso dos jogos para a aprendizagem no ensino superior. FAE- Caderno PAIC v.18, n.1, 2017. Disponível em: https://cadernopaic.fae.edu/cadernopaic/article/view/264/240. Acesso em 12 jan.2020. 
MACEDO, K. D. S. et al. Metodologias ativas de aprendizagem: caminhos possíveis para inovação no ensino em saúde. Escola Anna Nery, v.22, n.3, p.1-9, 2018.

MElO, A. C. A., ÁvilA, T. M., SANTOS, D. M. C. Utilização de jogos didáticos no ensino de ciências: um relato de caso. Ciência Atual, Rio de Janeiro, v.9, n.1, 2017. Disponível em: http://inseer.ibict.br/cafsj/index.php/cafsj/article/view/170. Acesso em: 23 mar.2020.

MESTANZA, P. O uso de jogos didáticos como abordagens alternativas para o ensino de bioquímica. Monografia (Curso de Ciências Biológicas) Universidade Federal de Uberlândia. 2017. Disponível em: https://repositorio.ufu.br/bitstream/123456789/19298/3/UsoJogosDidaticos.pdf Acesso em: 20 fev.2020

NETO, H. S. M.; MORADILLO, E. F. O jogo no ensino de química e a mobilização da atenção e da emoção na apropriação do conteúdo científico: aportes da psicologia histórico-cultural. Ciência \& Educação, v.23, n.2, p.523-540, 2017.

NOJOSA, A. C. B. et al. Criação de jogos didáticos como estratégia no ensino de bioquímica. Congresso Brasileiro de Química, 49, 2009, São Rafael, RS. Anais... São Rafael, RS, 2009.

PIRES, M. R. G. M.; GOTTEMS, L. B. D.; FONSECA, R. M. G. S. Recriar-se lúdico no desenvolvimento de jogos na saúde: referências teórico-metodológicas à produção de subjetividades. Texto Contexto Enfermagem, v.26, n.4, p.1-12, 2017.

RAMOS, E. S. et. al. O uso da ludicidade como ferramenta para o Ensino de Química Orgânica: o que pensam os alunos. ACTIO , Curitiba, v. 2, n. 2, p. 119-136, jul./set. 2017. ROSA, V. B. (2017) A construção do ensino-aprendizagem através do lúdico. In: Congresso de Ensino, Pesquisa e Extensão da UEG, v.4, 2017, Pirenópolis. Anais...Pirenópolis: UEG. Disponível em: https://www.anais.ueg.br/index.php/cepe/article/view/11012 Acesso em: 20 fev. 2020.

PIZUTTI, A. L. et al. Alternativas de ensino na disciplina de parasitologia veterinária da Unijuí/RS. Brazilian Journal of Animal Environment and Research. , Curitiba, v. 1, n. 1, p. 72-79, jul./set. 2018.

VERÍSSIMO, A. C. B.; SANTOS, A. M. Por que pensar o lúdico na universidade?. In: SIE - XV Seminário Internacional de Educação: Educação e Interdisciplinaridade percursos teóricos e metodológicos, 2016, Novo Hamburgo. Anais.... SIE - XV Seminário Internacional de Educação: Educação e Interdisciplinaridade percursos teóricos e metodológicos, 2016. v. 1. p. 1-1. 